\title{
Multimodal analysis of the effects of dexamethasone on high-altitude cerebral oedema: protocol for a pilot study
}

\author{
O. Fisher ${ }^{1,2^{*}}$ (D, R. A. Benson ${ }^{1,3}$, S. Wayte ${ }^{1}$, P. K. Kimani ${ }^{2}$, C. Hutchinson ${ }^{1,2}$ and C. H. E. Imray ${ }^{1,2}$
}

\begin{abstract}
Background: Acute mountain sickness (AMS) is a cluster of symptoms that commonly occur in those ascending to high altitudes. Symptoms can include headaches, nausea, insomnia and fatigue. Exposure to high altitude can also lead to high-altitude cerebral oedema (HACE), which is a potential cause of death whilst mountaineering. Generally, AMS precedes the development of HACE. Historical studies have demonstrated the effectiveness of regular dexamethasone administration in reducing the symptoms of AMS. However, the mechanism by which dexamethasone works to reduce symptoms AMS remains poorly understood. Further studies, simulating altitude using hypoxic tents, have characterised the effect of prolonged exposure to normobaric hypoxia on cerebral oedema and blood flow using MRI. This randomised trial assesses the effect of dexamethasone on hypoxia-induced cerebral oedema in healthy adult volunteers.

Methods/design: D4H is a double-blind placebo-controlled randomised trial assessing the effect of dexamethasone on hypoxia-induced cerebral oedema. In total, 20 volunteers were randomised in pairs to receive either $8.25 \mathrm{mg}$ dexamethasone or normal saline placebo intravenously after $8 \mathrm{~h}$ of hypoxia with an $\mathrm{FiO}_{2}$ of $12 \%$. Serial MRI images of the brain and spinal cord were obtained at hours $0,7,11,22$ and 26 of the study along with serum and urinary markers to correlate with the severity of cerebral oedema and the effect of the intervention.

Discussion: MRI has been used to identify changes in cerebral vasculature in the development of AMS and HACE. Dexamethasone is effective at reducing the symptoms of AMS; however, the mechanism of this effect is unknown. If this study demonstrates a clear objective benefit of dexamethasone in this setting, future studies may be able to demonstrate that dexamethasone is an effective therapy for oedema associated with brain and spinal cord ischaemia beyond AMS.
\end{abstract}

Trial registration: Clinicaltrials.gov, NCT03341676. Registered on 14 November 2017.

Keywords: Altitude, hypoxia, cerebral oedema, steroid, acute mountain sickness, MRI

\section{Background}

Acute mountain sickness (AMS) is a cluster of symptoms that commonly occur in those ascending to high altitudes (>1500 m), including headaches, nausea, insomnia and fatigue [1]. Exposure to high altitude can also lead to the more dangerous high-altitude cerebral oedema (HACE), which is a potential cause of death whilst mountaineering. Whether HACE and AMS

\footnotetext{
* Correspondence: owainfisher@doctors.org.uk

${ }^{1}$ University Hospital Coventry and Warwickshire, Clifford Bridge Road, Coventry CV2 2DX, UK

${ }^{2}$ University of Warwick, Coventry, UK

Full list of author information is available at the end of the article
}

belong to the same pathophysiological spectrum is a matter of debate, although generally AMS precedes the development of HACE.

Magnetic resonance imaging (MRI) studies have demonstrated the impact of prolonged periods at altitudes of up to $4350 \mathrm{~m}$ on cerebral white matter volume and cerebral blood flow. Hypoxia is associated with a compensatory increase in cerebral blood flow and a subsequent increase in brain volume, which can be demonstrated through MRI [2]. The increasing use of hypoxic tents to induce AMS has allowed interval imaging and a clearer demonstration of both the timing and patterns of

(C) The Author(s). 2019 Open Access This article is distributed under the terms of the Creative Commons Attribution 4.0 International License (http://creativecommons.org/licenses/by/4.0/), which permits unrestricted use, distribution, and 
oedema development in the brain [3]. MRI is useful for monitoring the brain during these periods, as directly measuring the intracranial pressure is difficult to do or justify in healthy volunteers whereas the intracranial pressure can be inferred indirectly using the change in the volume of different intracranial tissues [3]. Kallenberg et al. used diffusion-weighted imaging (DWI) to demonstrate that AMS sufferers have a decreased apparent diffusion coefficient (ADC), a measure of how freely water can move between tissues [4-6]. The drop in ADC suggests cytotoxic oedema is an important component of AMS. This mechanism has many similarities with the accepted pathophysiology of cytotoxic oedema during cerebral ischaemia [7]. Compared to healthy tissue, the ischaemic spinal cord, like the brain, also shows a drop in ADC on DWI accompanied by hyperintensity on T2-weighted imaging [8-11]. Zhang [11] used canine models to demonstrate that changes in DWI and T2weighted imaging are visible within an hour of inducing spinal cord ischaemia.

Double-blind studies simulating altitude have already demonstrated the effectiveness of regular dexamethasone administration in reducing the symptoms of AMS. Johnson et al. compared 6 hourly dexamethasone (4 mg dose) to a placebo in 16 men exposed to a simulated altitude of $4570 \mathrm{~m}$ using a hypobaric chamber [12]. A meta-analysis by Tang et al. [13] of using oral dexamethasone to treat AMS calculated an odds ratio of 6.03 (95\% confidence interval, 2.23-21.00, $p \geq 0.05$ ) compared to a placebo.

Multiple peripheral serum biomarkers of cerebral or blood-brain barrier dysfunction are currently under investigation; however, none have previously been applied to AMS and HACE. Glial fibrillary acidic protein (GFAP) is an intermediate filament protein that is upregulated in astrocytes following neuronal injury. There is good experimental correlation with neurological damage after a stroke or traumatic brain injury. Purine nucleosides (adenosine, inosine and hypoxanthine) have also been found to be sensitive early markers of ischaemic brain events $[14,15]$. $\alpha-1$ acid glycoprotein has recently been shown to act as a more sensitive marker of proteinuria than the more widely utilised urinary protein, albumin [16]. In animal models, the presence of proteinuria has been demonstrated to precede cerebral oedema and has been demonstrated to modulate the permeability of the blood-brain barrier [17, 18], as well as correlating with exposure to hypoxia [19].

Despite evidence for its efficacy, the mechanism behind the effect of dexamethasone remains poorly understood. Therefore, it has not been validated as a true therapeutic solution to AMS or HACE. This study aims to provide evidence of the mechanisms of action and therapeutic potential of dexamethasone for the treatment of symptomatic AMS and other causes of cerebral and spinal cord oedema and to investigate and correlate changes in peripheral serum biomarkers in response to hypoxia with radiological findings.

\section{Methods/design \\ Study design}

D4H is a phase-I double-blind placebo-controlled randomised control trial assessing the effect of dexamethasone on hypoxia-induced cerebral oedema in healthy adult volunteers.

\section{Hypothesis}

A single dose of intravenous dexamethasone given after 8 hours in normobaric hypoxia at $12 \%$ inspired oxygen concentration $(\mathrm{FiO} 2)$ reduces the incidence or severity of the symptoms of AMS, as determined by MRI changes due to cerebral oedema.

\section{Primary objective}

To identify any measurable differences in:

1. Lake Louise scores

2. prespecified MRI parameters

following prolonged normobaric hypoxia after administration of a single dose of intravenous dexamethasone compared to a placebo.

\section{Secondary objectives}

1. To measure the integrity of the blood-brain barrier and astrocyte dysfunction using proxy measurements (serum purine levels and GFAP) and correlate these with primary outcome measures.

2. To correlate proteinuria with the primary outcome measures.

\section{Sample size}

Estimates from our previous observational study of MRI differences at normobaric hypoxia were used to determine the power [3]. It was assumed that dexamethasone will reverse outcome measures to their baseline values. Powers for pairwise comparisons at $22 \mathrm{~h}$ for three different significance levels $(0.05,0.10$ and 0.20$)$ and for three outcome measures that showed change at $22 \mathrm{~h}$ from baseline in the observational work were calculated by assuming that the data are normally distributed, (Table 1). Since most of the other outcomes showed smaller differences, it was decided to test hypotheses at 20\% significance and make this study a pilot study. 
Table 1 Power for different outcomes and significance levels

\begin{tabular}{lllllll}
\hline Outcome & Estimates from Sagoo et al. [3] & & Power & \\
\cline { 2 - 3 } & Difference & Standard deviation & & $a=0.05$ & $a=0.10$ & $a=0.20$ \\
\hline Blood oxygen content, $\mathrm{ml} \mathrm{O} / \mathrm{dL}$ blood & 2.05 & 1.33 & 97 & 98 & 99 \\
Whole-brain ADC $\times 10^{-4} / \mathrm{mm}^{3}$ & 0.5 & 0.45 & 78 & 86 & 93 \\
Corpus callosum (genu) $\mathrm{ADC} \times 10^{-4} / \mathrm{mm}^{3}$ (mean of right and left) & 1.35 & 1.65 & 52 & 64 & 77 \\
\hline
\end{tabular}

$A D C$ apparent diffusion coefficient

\section{Inclusion and exclusion criteria}

Subjects between the ages of 18 and 35 with a body mass index $<30 \mathrm{~kg} / \mathrm{m}^{2}$ who have not been to an altitude greater than $1500 \mathrm{~m}$ within 12 weeks were invited to participate. They provided written informed consent, which was obtained by a medically qualified doctor, as delegated by the chief investigator.

Patients with any systemic illness, currently pregnant or breastfeeding, or with recorded contra-indications to taking dexamethasone or having an MRI were excluded. Patients with a medical history of hypertension, untreated respiratory disease, glaucoma, epilepsy, peptic ulcer, recent surgery or known intra-cranial pathology were also ineligible.

\section{Randomisation}

Once eligibility had been confirmed, participants were allocated to the treatment or placebo group via block randomisation. The participants were randomised in sex-matched pairs and the randomisation sequence allocated participants attending on the same day to the same study arm to prevent unintentional unblinding of participants or investigators during the visit. The randomisation list was generated by computer by a statistician. Except in the case of an adverse event (AE) requiring unblinding, only the statistician who generated the list and the pharmacist are not blinded to study allocation. They are not members of the trial management group.

\section{Intervention}

Subjects in the placebo group received a single dose of $0.9 \%$ sodium chloride $(8.2 \mathrm{~mL})$ as the placebo, which was administered as a bolus injection intravenously over 5 min at $8 \mathrm{~h}$ post-baseline $(0 \mathrm{~h})$. Subjects in the intervention group received a single dose of dexamethasone 8.25 mg $(2.5 \mathrm{~mL})$ made up to $8.2 \mathrm{~mL}$ with $0.9 \%$ sodium chloride, which also was administered as a bolus injection intravenously over $5 \mathrm{~min}$ at $8 \mathrm{~h}$ post-baseline $(0 \mathrm{~h})$.

\section{Schedule of events}

Each subject visited the study site twice, the first time for a screening and consent visit and the second time for a period of $26 \mathrm{~h}$ for the study itself. A diagrammatic representation of patient flow through the trial is shown in Fig. 1. A full schedule of investigations, interventions and procedures to be performed at each study visit is shown in Table 2.

\section{Visit 1 - Screening}

Volunteers were invited to attend University Hospitals Coventry and Warwickshire NHS Trust (UHCW) for screening and enrolment. Screening included baseline observations, a comprehensive health and MRI eligibility questionnaire, a pregnancy test if applicable and baseline blood tests. Consent included entering their personal information into the Health Research Authority's OverVolunteering Prevention System (TOPS). Once a potential participant had provided permission, the researcher sent a letter and copy of the participant information sheet to the participant's general practitioner to inform them of their participation in the study.

\section{Visit 2 - Intervention}

Confirmation of eligibility and safety checks The interventional study visit took place over $26 \mathrm{~h}$ in the MRI suite at UHCW. Any participants failing to meet the eligibility criteria on the day of intervention were withdrawn from the trial. Information on the last urine void time, a Lake Louise Acute Mountain Sickness selfassessment score, venous blood samples and baseline observations were recorded. The first MRI scan was then performed and used for baseline values.

Hypoxication Following the assessment at hour 0, participants experienced $24 \mathrm{~h}$ of normobaric hypoxia at specific oxygen concentrations using a hypoxication tent (Everest Summit Hypoxic Generator, Hypoxic Systems, New York). The hypoxication tent is a self-contained structure measuring approximately $2 \mathrm{~m}(\mathrm{w}) \times 2.5 \mathrm{~m}(\mathrm{l}) \times$ $1.8 \mathrm{~m} \mathrm{(h),} \mathrm{in} \mathrm{which} \mathrm{the} \mathrm{oxygen} \mathrm{levels} \mathrm{are} \mathrm{tightly} \mathrm{con-}$ trolled. Participants may leave the tent during the intervention, during which time they will wear a mask attached to a portable hypoxicator to make sure the inspired oxygen concentrations are controlled. Participants will continue with normal activities while in the tent, such as eating and sleeping. The time from which the participant begins to inspire hypoxicated air $\left(\mathrm{FiO}_{2} 12 \%\right)$ marks the start of hour 1 . Subsequent observations were taken on the hour, plus or minus $30 \mathrm{~min}$ to allow for 


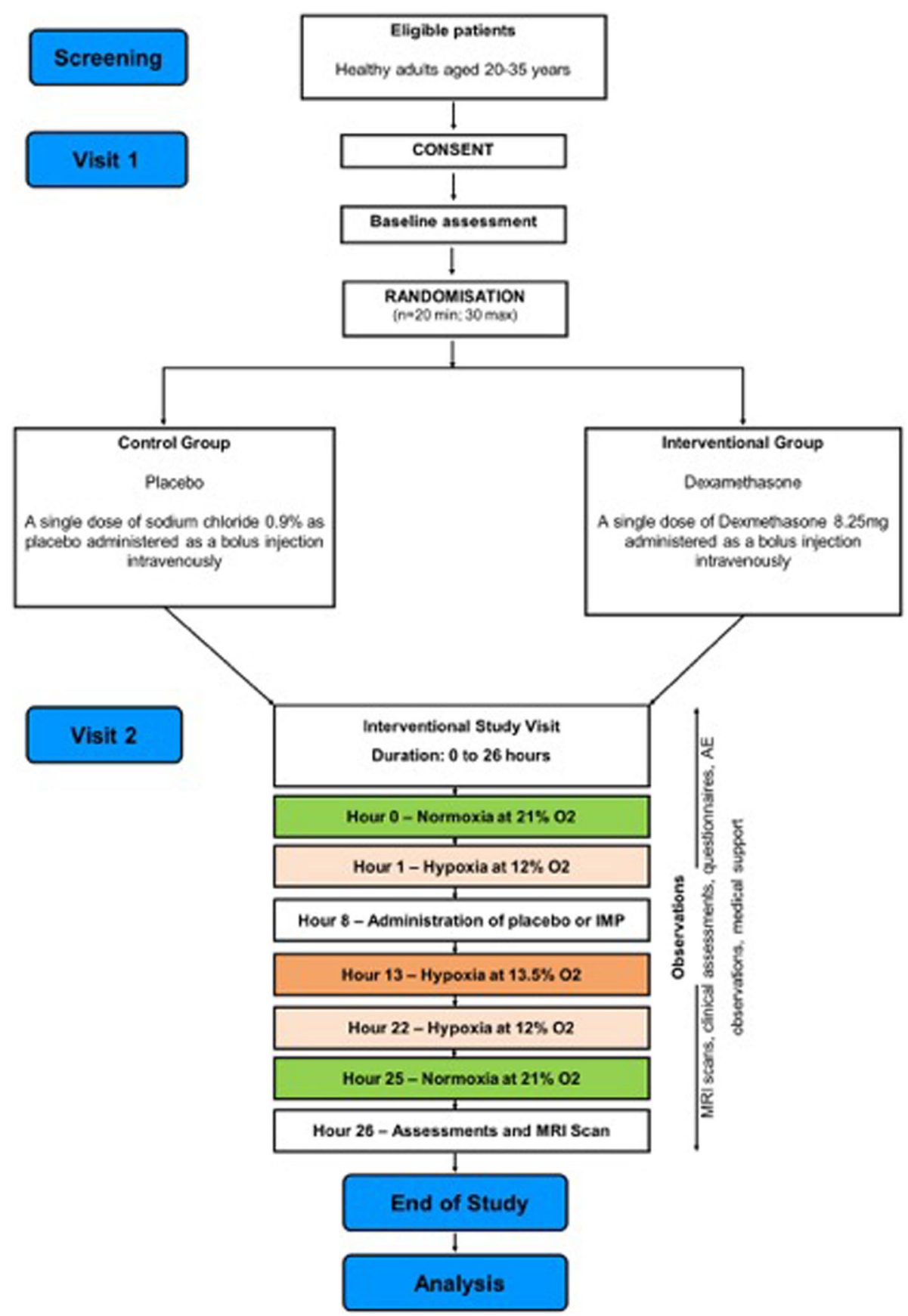

Fig. 1 Participant flow diagram. IMP investigational medicinal product

any unanticipated delays during the study visit. At hour 25 , the participant returned to breathing oxygen at normal atmospheric pressure $\left(\mathrm{FiO}_{2} 21 \%\right)$. The hypoxication schedule is shown in Table 3.

Three hypoxic generators were used to control the environment. Carbon dioxide build-up was controlled with an air pump (Bair Hugger ${ }^{\mathrm{m}}$, 3M, Berkshire, UK). Air from the tent was pumped through two soda lime scrubbers (Spherasorb $^{\text {tw }}$, medical grade soda lime from
Intersurgical Ltd, UK, in canisters by Draeger Medical UK Ltd). These were replaced after $12 \mathrm{~h}$.

\section{Outcome measures}

MRI Sequences performed in the brain have previously been found to produce significant results [3]. This imaging included assessment of the diameter and flow rate within the middle cerebral artery using 3D time of flight 


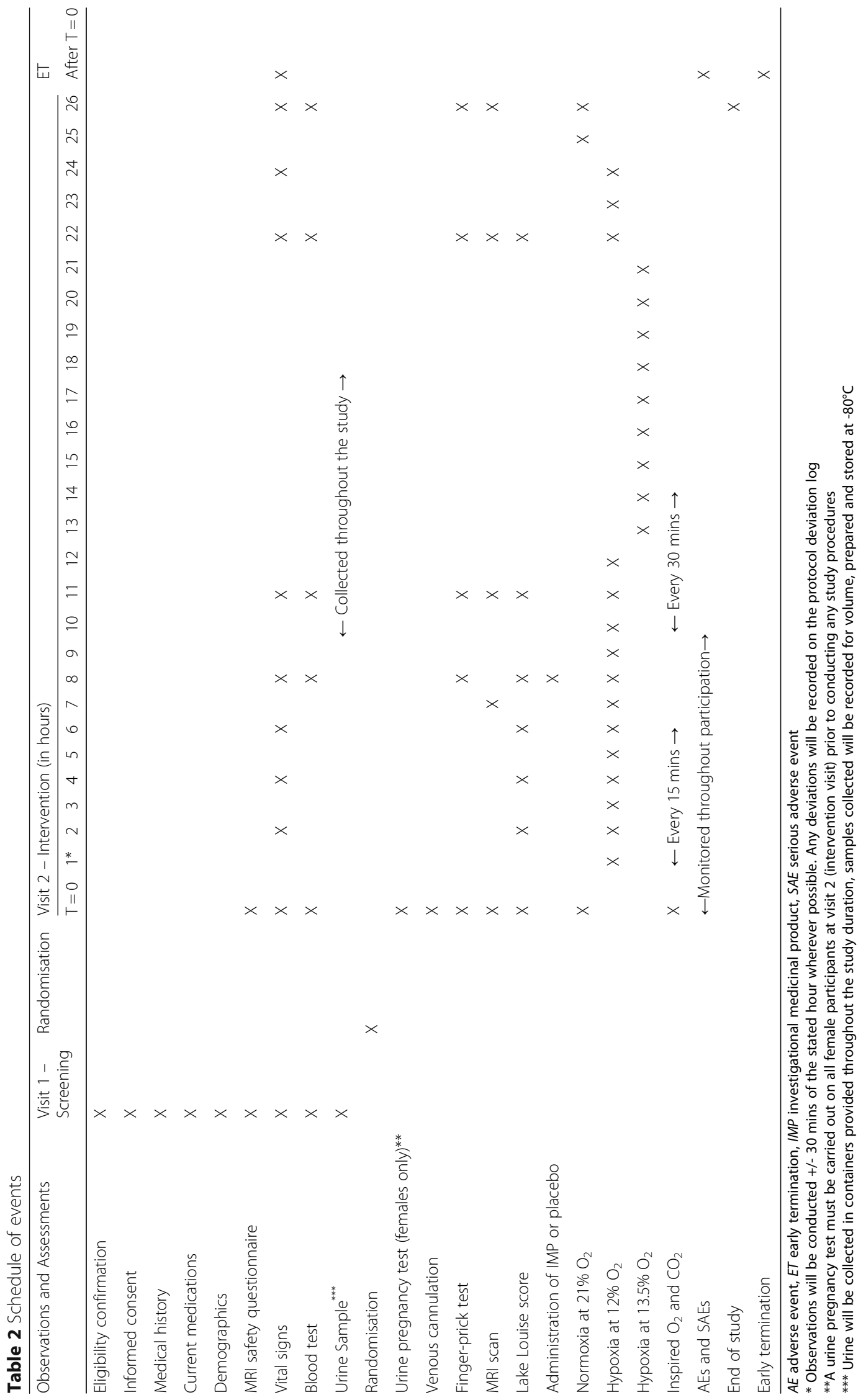


Table 3 Schedule of participant hypoxication

\begin{tabular}{ll}
\hline Timeline & Inspired oxygen concentration $\left(\mathrm{FiO}_{2}\right)$ \\
\hline Baseline & Normal atmospheric $\mathrm{O}_{2}(21 \%)$ \\
Hours $1-12$ & $12 \%$ \\
Hours $13-21$ & $13.5 \%$ \\
Hours $22-24$ & $12 \%$ \\
Hours $25-26$ & Normal atmospheric $\mathrm{O}_{2}(21 \%)$ \\
\hline
\end{tabular}

and 2D phase contrast MR angiography, respectively. In the present study, whole-brain DWI was used to produce ADC maps to quantify brain oedema. A T1weighted total brain volume sequence was used to calculate changes in brain parenchymal and cerebrospinal fluid volumes as a result of cerebral oedema. T2*-based susceptibility-weighted imaging identified changes in the deep cerebral venous anatomy and found evidence of venous compression secondary to cerebral oedema. In addition, sequences were acquired to assess the cervical spinal cord volume and the total cord length. The flow rate in the internal carotid artery was measured using 2D phase-contrast MR angiography. The acquisition parameters used for all the MR sequences are given in Table 4.

Blood sampling Venous blood was taken immediately prior to each MRI scan and haematology and biochemistry markers were measured, including full blood count, renal function, erythrocyte sedimentation rate and levels of C-reactive protein. Serum samples were stored immediately at $-80^{\circ} \mathrm{C}$ for a later GFAP analysis. Finger-prick capillary blood samples for purine assessment were also obtained at these time points.
Urine samples Urine samples were collected and processed for every urine void during the intervention. The samples collected will be a spun down via centrifuge and were stored in a monitored freezer set to maintain temperatures of $-70^{\circ}$ to $-85^{\circ} \mathrm{C}$. Samples were frozen within 1 hour of collection.

Clinical assessments Vital signs were monitored every $2 \mathrm{~h}$ between hours $0-11$ and hours 22-26. After the MRI scan at hour 0 , the scans were repeated at hours 7 , 11, 22 and 26. Participants were asked to complete the Lake Louise Acute Mountain Sickness Questionnaire at hours 2, 4, 6, 8, 11, 22 and 26. The Lake Louise score is a validated tool for diagnosing and scoring the severity of AMS [20]. Five questions (headache, gastrointestinal upset, fatigue, dizziness and sleep disturbance) were graded 0 (none) to 3 (severe) by participants. A total score of 3 is considered diagnostic of AMS. A score of 6-9 is considered moderate AMS and a score of 10 or above is considered severe AMS. In this study, the Lake Louise score was used to monitor participants for the development of AMS. If a participant had a score of 6 or above or an increase in total score of 2 or greater from the previous score, then consideration was made about withdrawing them from the study. Inspired $\mathrm{O}_{2}$ and $\mathrm{CO}_{2}$ were measured every $15 \mathrm{~min}$ from hours 1 to 9 and thereafter every $30 \mathrm{~min}$ from hours 10 to 24 .

Preparation, storage and administration of the investigational medicinal product The investigational medicinal product (IMP) was prepared for administration, labelled and stored in the trust's aseptic laboratory for a maximum of $24 \mathrm{~h}$ prior to the study visit. Dexamethasone

Table 4 Technical MRI sequence parameters

\begin{tabular}{|c|c|c|c|c|c|c|c|c|c|}
\hline Sequence & Purpose & $\begin{array}{l}\text { TR } \\
\text { (ms) }\end{array}$ & $\begin{array}{l}\mathrm{TE} \\
\text { (ms) }\end{array}$ & $\begin{array}{l}\text { Flip } \\
\text { angle }\left(^{\circ}\right)\end{array}$ & $\begin{array}{l}\text { FoV } \\
(\mathrm{mm})\end{array}$ & Matrix & $\begin{array}{l}\text { Slice width/ } \\
\text { slice gap (mm) }\end{array}$ & $\begin{array}{l}\text { Acquisition } \\
\text { time }\end{array}$ & Comment \\
\hline 3D time of flight & Asses diameter MCA & 27 & 5.7 & 20 & $210 \times 210$ & $384 \times 256$ & $1.2 / 0.0$ & $3 \min 10 s$ & \\
\hline 2D phase contrast & Assess flow in MCA & 11 & 5.2 & 30 & $160 \times 160$ & $256 \times 224$ & 5.0 & $4 \min 7 s$ & $\begin{array}{l}1 \text { slice, } 25 \text { phases } \\
\text { venc }=120 \mathrm{~cm} \mathrm{~s}^{-1}\end{array}$ \\
\hline $\begin{array}{l}\text { Diffusion-weighted } \\
\text { imaging }\end{array}$ & $\begin{array}{l}\text { Produce ADC maps to } \\
\text { quantify brain oedema }\end{array}$ & $\begin{array}{l}13 \\
729\end{array}$ & 86.2 & - & $240 \times 240$ & $256 \times 256$ & $4.0 / 1.0$ & $\begin{array}{l}5 \mathrm{~min} \\
57 \mathrm{~s}\end{array}$ & $\begin{array}{l}b=0,800 \text { and } 1000 \\
\text { s.mm }\end{array}$ \\
\hline T1 3D FSPGR & $\begin{array}{l}\text { Assess brain and CSF } \\
\text { volume }\end{array}$ & 8.5 & 3.3 & 12 & $240 \times 180$ & $256 \times 256$ & $1.8 / 0.0$ & $5 \min$ & $\begin{array}{l}\mathrm{TI}=400 \mathrm{~ms} \text { Reconstructed } \\
\text { to } 0.9 \mathrm{~mm} \text { slice width }\end{array}$ \\
\hline SWI & $\begin{array}{l}\text { Changes in venous } \\
\text { volume }\end{array}$ & 50.9 & 23.7 & 10 & $240 \times 240$ & $320 \times 288$ & $2.0 / 0.0$ & $\begin{array}{l}6 \mathrm{~min} \\
41 \mathrm{~s}\end{array}$ & $\begin{array}{l}\text { Reconstructed to } 1 \mathrm{~mm} \\
\text { slice width }\end{array}$ \\
\hline T2 3D FSE (cube) & $\begin{array}{l}\text { Volume of the } \\
\text { cervical spinal cord }\end{array}$ & 1250 & 92.2 & - & $180 \times 180$ & $288 \times 288$ & $2.0 / 0.0$ & $3 \min 35 s$ & $\begin{array}{l}\text { Reconstructed to } 1 \mathrm{~mm} \\
\text { slice width }\end{array}$ \\
\hline Sagittal T2 & $\begin{array}{l}\text { Assess total cord } \\
\text { length }\end{array}$ & 3406 & 106.3 & - & $440 \times 440$ & $384 \times 288$ & $4.0 / 0.0$ & $1 \min 56 s$ & $\begin{array}{l}\text { Images combined to } \\
\text { produce a single image }\end{array}$ \\
\hline 2D phase contrast & $\begin{array}{l}\text { Assess flow in the } \\
\text { internal carotid arteries }\end{array}$ & 10.5 & 4.9 & 30 & $160 \times 160$ & $256 \times 224$ & 5.0 & $4 \min 21 \mathrm{~s}$ & $\begin{array}{l}1 \text { slice, } 25 \text { phases } \\
\text { venc }=120 \mathrm{~cm} \mathrm{~s}^{-1}\end{array}$ \\
\hline
\end{tabular}

$A D C$ apparent diffusion coefficient, CSF cerebrospinal fluid, FoV field of view, FSE fast spin echo, FSPGR fast spoiled gradient echo, MCA middle cerebral artery, $S W I$ susceptibility-weighted imaging, $T E$ echo time, $T$ inversion time, $T R$ repetition time 
must not be stored above $25^{\circ} \mathrm{C}$ and cannot be refrigerated or frozen. The study medication was stored in a temperature-controlled box. A temperature log ensured it remained within the acceptable temperature range until use. Any medication found to have breached the specified temperature range was discarded. On the intervention day, a member of the study team collected the prepared IMP for administration to the participants. Participants were randomised to receive a single dose of either the placebo or dexamethasone at hour 8 of the intervention visit. A medical doctor, as delegated by the chief investigator, prescribed and administered the study medication.

\section{Statistical analysis}

Summary of baseline data and flow of patients Data exploration will include comparing the baseline characteristics of the volunteers in the placebo and dexamethasone groups. For continuous characteristics such as age, we will report the mean, median, range, interquartile range and standard deviation. Differences between the two groups will be compared using the Mann-Whitney $U$ test. For categorical data such as gender, we will report the number and percentage of cases in each category. Fisher's exact test will be used to compare the two groups.

Statistical analysis plan As in Sagoo et al. [3], it thought plausible to assume that the outcomes would be normally distributed. We will assess this assumption using the residuals from models that assume the data are normally distributed. If the residuals are not normally distributed, we will transform the raw data and repeat the normality assumption check.

Ultimately the primary aim of the study is to compare outcomes between placebo and dexamethasone groups at $22 \mathrm{~h}$. The comparisons could be made by performing $t$-tests using data collected at $22 \mathrm{~h}$. This is, however, inefficient and so potentially to increase power, we will include outcome measures for all time points. To account for the correlation among measurements taken from the same volunteer at multiple time points, we will analyse data by fitting linear mixed models. Separate linear mixed models will be fitted for different outcomes. Each linear mixed model will include a fixed term(s) for the time at which a measurement was taken, a fixed term for the treatment group of the volunteer and an interaction term for time and treatment group. The interaction term enables us to make inference for the mean difference between the placebo and dexamethasone groups at different time points. If there is an imbalance of a baseline characteristic, a fixed term for the characteristic will be included in the model. Outcome measurement profiles over time will be assessed first. If the relationship is approximately linear, a linear term for time will be fitted. If not, time will be taken as a categorical variable.

For data taken at $22 \mathrm{~h}$, we will report the estimated mean differences, the $95 \%$ confidence interval for the mean differences of the primary outcome measures and $p$ values to test the hypothesis that the mean difference is zero. As mentioned previously, because this is a pilot study, the hypothesis will be tested at a $20 \%$ significance level. Also, for the same reason, we will not adjust for multiple hypotheses (corresponding to different outcome measures).

The above analysis plan will be used if it is plausible to assume that the data are normally distributed. If a transformation does not achieve normality, we will use nonparametric methods such as the Mann-Whitney U test.

\section{Participant withdrawal criteria}

A participant would be withdrawn from the study during the interventional visit in the following circumstances:

1. If the participant scores 'severe' for more than one symptom on the Lake Louise Mountain Sickness Score Questionnaire.

2. If it becomes medically necessary in the opinion of the clinician overseeing the study visit.

3. The participant requests to be withdrawn at any time.

In the event of withdrawal, the researcher will record the reason for discontinuation and any AEs in the participant's notes.

\section{Trial stopping rules}

The trial will be stopped if:

1. A serious adverse reaction occurs that may be related to the administration of the IMP to a participant.

2. A severe non-serious adverse reaction occurs that may be related to the IMP, regardless of the system and organ class, to two participants.

In these circumstances, the trial steering committee, data-monitoring committee, sponsor, research ethics committee and the Medicines and Healthcare Products Regulatory Agency will be notified within $24 \mathrm{~h}$ of receipt of the initial report. Any participants actively involved in the trial will be withdrawn and all trial activities will be immediately discontinued.

\section{Participant safety}

A clinical member of the study staff was present in the study area at all times during the interventional study visit. Participants' vital signs were monitored throughout 
the intervention period, except for hours 12-21, when it was expected that the participant would be sleeping, unless the participant became unwell. A thorough risk assessment of the study area was undertaken and approved. Unblinding of investigators and participants is permitted in the event of any AE, serious adverse event (SAE) or suspected unexpected serious adverse reaction (SUSAR). Unblinding will take place via codebreak envelopes stored within the MRI suite and pharmacy at UHCW.

\section{Trial oversight}

Trial oversight is provided by the trial management group. The trial steering committee will meet regularly to review progress and the safety of the study. There is also an independent data management group. The study sponsor, UHCW, is a National Institute for Health Research facility. The study was reviewed after the first two participants to ensure the safety and quality measures were met. After 20 patients had completed the protocol, a preliminary analysis was performed, and if sufficient differences had been seen, the study would have been closed to recruitment. If not, recruitment will continue to 30 patients. All potential AEs, as defined by good clinical practice (AEs, SAEs or SUSARs), were compiled by the trial manager and statistician and reviewed by the sponsor. All Grade IV AEs, all SAEs and all SUSARs were reported to the trial management group within 24 h. Participant information will be held securely at the trial sponsor site until study closeout, when they will be transferred to a third-party storage facility with appropriate security, and fire and flood provisions.

\section{Discussion}

Previous studies have used MRI to identify changes in cerebral vasculature in the development of AMS and HACE. Since dexamethasone is therapeutic in this setting, the next stage of research is to demonstrate that dexamethasone administration has a direct effect on cerebral vasculature during a prolonged period of normobaric hypoxia to provide evidence of the mechanisms behind the development of AMS. If this study demonstrates a clear benefit of dexamethasone in this setting, the aim is to conduct further studies to include patients suffering from similar cerebral and spinal cord oedema due to other causes of cerebral hypoxia and spinal cord ischaemia. Ultimately, we would like to discover whether dexamethasone is an effective therapy for oedema associated with brain and spinal cord ischaemia.

\section{Trial status}

This is protocol version 2.0, dated 25 July 2018. The scheduled start of recruitment was 2 February 2019. The anticipated end of recruitment was March 2020.

\section{Abbreviations}

ADC: Apparent diffusion coefficient; AE: Adverse event; AMS: Acute mountain sickness; DWI: Diffusion-weighted imaging; GFAP: Glial fibrillary acidic protein; HACE: High-altitude cerebral oedema; IMP: Investigational medicinal product; MRI: Magnetic resonance imaging; SAE: Serious adverse event;

SUSAR: Suspected unexpected serious adverse reaction; SWI: Susceptibilityweighted imaging; UHCW: University Hospitals Coventry and Warwickshire NHS Trust

\section{Acknowledgements}

This publication presents independent research funded by the Jabbs Foundation and carried out with the support of the Coventry and Warwickshire Clinical Research Facility of the National Institute for Health Research. The views expressed are those of the authors and not necessarily those of the Jabbs Foundation, the NHS, the National Institute for Health Research or the Department of Health.

The authors would like to thank Mojid Khan, lead clinical trials pharmacist at UHCW, Philippa Tilby, a research pharmacist at UHCW, Julie Jones, a research nurse at UHCW, Mr Michael Diokno and Mr Adam Ryder, research radiographers at UHCW, and Mr Shivam Joshi and Mr Kavi Sharma of the Research, Development and Innovation Department, UHCW.

\section{Authors' contributions}

OF wrote the manuscript. RAB was responsible for study design, writing of the manuscript and a critical revision of the manuscript. SW was responsible for the design and implementation of the radiological protocol, writing of the radiological section of the manuscript and a critical revision of the manuscript. PK was responsible for the design and implementation of the randomisation protocol, the statistical analysis plan and the data analysis. $\mathrm{CH}$ designed the radiological protocols, interpreted the imaging and critically revised the manuscript. CHEl was responsible for the study design and a critical revision of the manuscript. All authors read and approved the final manuscript.

\section{Funding}

This study is funded by the Jabbs Foundation, Birmingham, UK (registered charity number 1128402). The sponsor is UHCW. The funder and sponsor had no input into study design, data collection, data analysis or writing of this manuscript

\section{Availability of data and materials}

The datasets generated and analysed during the current study will be available from the corresponding author or chief investigator on reasonable request.

\section{Ethics approval and consent to participate}

Informed written consent was obtained from all participants prior to enrolment into the trial. The protocols described here received approval from the Westminster Research and Ethics Committee on 19 April 2018 (reference 18/LO/0309) and was registered with clinicaltrials.gov (NCT03341676, https://clinicaltrials.gov/ct2/show/NCT03341676) on 14 November 2017.

\section{Consent for publication}

Not applicable.

\section{Competing interests}

The authors declare that they have no competing interests.

\section{Author details}

${ }^{1}$ University Hospital Coventry and Warwickshire, Clifford Bridge Road, Coventry CV2 2DX, UK. ${ }^{2}$ University of Warwick, Coventry, UK. ${ }^{3}$ University of Birmingham, Birmingham, UK.

Received: 1 March 2019 Accepted: 25 August 2019

Published online: 24 October 2019

\section{References}

1. Singh I, Khanna PK, Srivastava MC, Lal M, Roy SB, Subramanyam CS. Acute mountain sickness. N Engl J Med. 1969;280(4):175-84 PubMed PMID: 5782719. eng. 
2. Verges S, Rupp T, Villien M, Lamalle L, Troprés I, Poquet C, et al. Multiparametric magnetic resonance investigation of brain adaptations to 6 days at 4350 m. Front Physiol. 2016;7:393 PubMed PMID: 27660613. Pubmed Central PMCID: PMC5014870. Epub 2016/09/08. eng.

3. Sagoo RS, Hutchinson CE, Wright A, Handford C, Parsons H, Sherwood V, et al. Magnetic Resonance investigation into the mechanisms involved in the development of high-altitude cerebral edema. J Cereb Blood Flow Metab. 2017;37(1):319-31 PubMed PMID: 26746867. Pubmed Central PMCID: PMC5167111. Epub 2016/01/08. eng.

4. Kallenberg K, Bailey DM, Christ S, Mohr A, Roukens R, Menold E, et al. Magnetic resonance imaging evidence of cytotoxic cerebral edema in acute mountain sickness. J Cereb Blood Flow Metab. 2007;27(5):1064-71 PubMed PMID: 17024110. Epub 2006/10/04. eng.

5. Schoonman GG, Sándor PS, Nirkko AC, Lange T, Jaermann T, Dydak U, et al. Hypoxia-induced acute mountain sickness is associated with intracellular cerebral edema: a 3 T magnetic resonance imaging study. J Cereb Blood Flow Metab. 2008;28(1):198-206 PubMed PMID: 17519973. Epub 2007/05/23. eng.

6. Hunt JS, Theilmann RJ, Smith ZM, Scadeng M, Dubowitz DJ. Cerebral diffusion and T(2): MRI predictors of acute mountain sickness during sustained high-altitude hypoxia. J Cereb Blood Flow Metab. 2013;33(3):37280 PubMed PMID: 23211961. Pubmed Central PMCID: PMC3587813. Epub 2012/12/05. eng.

7. Baker LL, Kucharczyk J, Sevick RJ, Mintorovitch J, Moseley ME. Recent advances in MR imaging/spectroscopy of cerebral ischemia. AJR Am J Roentgenol. 1991;156(6):1133-43 PubMed PMID: 2028855. eng.

8. Loher TJ, Bassetti CL, Lövblad KO, Stepper FP, Sturzenegger M, Kiefer C, et al. Diffusion-weighted MRI in acute spinal cord ischaemia. Neuroradiology. 2003; 45(8):557-61 PubMed PMID: 12830338. Epub 2003/06/27. eng.

9. Nogueira RG, Ferreira R, Grant PE, Maier SE, Koroshetz WJ, Gonzalez RG, et al. Restricted diffusion in spinal cord infarction demonstrated by magnetic resonance line scan diffusion imaging. Stroke. 2012;43(2):532-5 PubMed PMID: 22033988. Epub 2011/10/27. eng.

10. Thurnher MM, Bammer R. Diffusion-weighted MR imaging (DWI) in spinal cord ischemia. Neuroradiology. 2006;48(11):795-801 PubMed PMID: 16977443. Epub 2006/09/15. eng.

11. Zhang JS, Huan Y, Sun LJ, Ge YL, Zhang XX, Chang YJ. Temporal evolution of spinal cord infarction in an in vivo experimental study of canine models characterized by diffusion-weighted imaging. J Magn Reson Imaging. 2007; 26(4):848-54 PubMed PMID: 17896378. eng.

12. Johnson TS, Rock PB, Fulco CS, Trad LA, Spark RF, Maher JT. Prevention of acute mountain sickness by dexamethasone. N Engl J Med. 1984;310(11): 683-6 PubMed PMID: 6700643. eng.

13. Tang $E$, Chen $Y$, Luo Y. Dexamethasone for the prevention of acute mountain sickness: systematic review and meta-analysis. Int J Cardiol. 2014; 173(2):133-8 PubMed PMID: 24679688. Epub 2014/03/15. eng.

14. Berne M, Rubio R, Curnish R. Release of adenosine from ischemic brain effect on cerebral vascular resistance and incorporation into cerebral adenine nucleotides. Circ Res. 1974;35(2):262-71.

15. Tian F, Bibi F, Dale N, Imray CHE. Blood purine measurements as a rapid real-time indicator of reversible brain ischaemia. Purinergic Signal. 2017; 13(4):521-8 PubMed PMID: 28803399. Pubmed Central PMCID: PMC5714841. Epub 2017/08/12. eng.

16. Talks B, Bradwell S, Delamere J, Rayner W, Clarke A, Christopher L, et al. Urinary alpha-1-acid glycoprotein is a sensitive marker of glomerular protein leakage at altitude. High Alt Med Biol. 2018;19(3):295-8.

17. Blezer EL, Nicolay K, Koomans HA, Joles JA. Losartan versus enalapril on cerebral edema and proteinuria in stroke-prone hypertensive rats. Am J Hypertens. 2001;14(1):54-61 PubMed PMID: 11206680. Epub 2001/02/24.

18. Yuan W, Li G, Zeng M, Fu BM. Modulation of the blood-brain barrier permeability by plasma glycoprotein orosomucoid. Microvasc Res. 2010; 80(1):148-57 PubMed PMID: 20362593. Epub 2010/04/07.

19. Winterborn MH, Bradwell AR, Chesner IM, Jones GT. The origin of proteinuria at high altitude. Postgrad Med J. 1987;63(737):179-81.

20. Roach RC, Hackett PH, Oelz O, Bärtsch P, Luks AM, Maclnnis MJ, et al. The 2018 Lake Louise Acute Mountain Sickness Score. High Alt Med Biol. 2018; 19(1):4-6 PubMed PMID: 29583031. Pubmed Central PMCID: PMC6191821. Epub 2018/03/13. eng.

\section{Publisher's Note}

Springer Nature remains neutral with regard to jurisdictional claims in published maps and institutional affiliations.

Ready to submit your research? Choose BMC and benefit from:

- fast, convenient online submission

- thorough peer review by experienced researchers in your field

- rapid publication on acceptance

- support for research data, including large and complex data types

- gold Open Access which fosters wider collaboration and increased citations

- maximum visibility for your research: over $100 \mathrm{M}$ website views per year

At $\mathrm{BMC}$, research is always in progress.

Learn more biomedcentral.com/submissions 